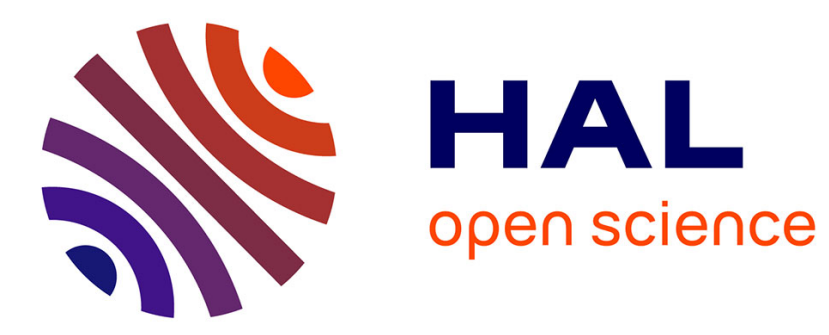

\title{
PROCESSING REQUIREMENTS FOR SYNTHETIC APERTURE SONAR SYSTEMS
}

\author{
M. Lawlor, A. Adams, O. Hinton, B. Sharif
}

\section{To cite this version:}

M. Lawlor, A. Adams, O. Hinton, B. Sharif. PROCESSING REQUIREMENTS FOR SYNTHETIC APERTURE SONAR SYSTEMS. Journal de Physique IV Proceedings, 1992, 02 (C1), pp.C1-981-C1984. 10.1051/jp4:19921215. jpa-00251182

\section{HAL Id: jpa-00251182 https://hal.science/jpa-00251182}

Submitted on 1 Jan 1992

HAL is a multi-disciplinary open access archive for the deposit and dissemination of scientific research documents, whether they are published or not. The documents may come from teaching and research institutions in France or abroad, or from public or private research centers.
L'archive ouverte pluridisciplinaire HAL, est destinée au dépôt et à la diffusion de documents scientifiques de niveau recherche, publiés ou non, émanant des établissements d'enseignement et de recherche français ou étrangers, des laboratoires publics ou privés. 


\title{
PROCESSING REQUIREMENTS FOR SYNTHETIC APERTURE SONAR SYSTEMS
}

\author{
M.A. LAWLOR, A.E. ADAMS, O.R. HINTON and B. SHARIF \\ Department of Electrical and Electronic Engineering, University of Newcastle upon Tyne, \\ GB-Tyne \& Wear NE1 7RU, Great-Britain
}

\begin{abstract}
This paper develops expressions which relate the parameters of a sonar to the processing power and memory required for the system. These expressions can be used when designing a sonar to ensure that realistic demands are placed on the processing engine. Benchmark test results are also presented for simulation algorithms running on a variety of machines.

RÉSUMÉ - Ce document développe des expressions mettant en relation les paramêtres d'un sonar avec la puissance et la mémoire traitements requises pour le système. Ces expressions peuvent être utilisées lois de l'étude du sonar de façon à s'assurer que les exigences réelles sont placées sur l'appareil traitant. Les résultats des tests de repérage sont également donnés pour les simulations algorithmiques d'une variété de machines.
\end{abstract}

\section{INTRODUCTION}

High resolution mapping of the sea-bed has traditionally been met by side-scan sonars. In radar, synthetic aperture processing is applied to side-scan systems to improve the resolution and this technique is now being investigated for side-scan sonar systems. The side-scan technique involves towing a transducer array along a straight path at a constant velocity. Sound is transmitted in a beam perpendicular to the motion of the transducer (fig 1). Range (acrosstrack) resolution is obtained by either transmitting a short pulse, or by transmitting a longer modulated pulse which can later be compressed into a short pulse. Azimuth (along-track) resolution is obtained by using a narrow beam, which means that a traditional side-scan sonar needs to operate at a high frequency which in turn reduces the operating range or with a long antenna which makes the system more costly and more cumbersome.
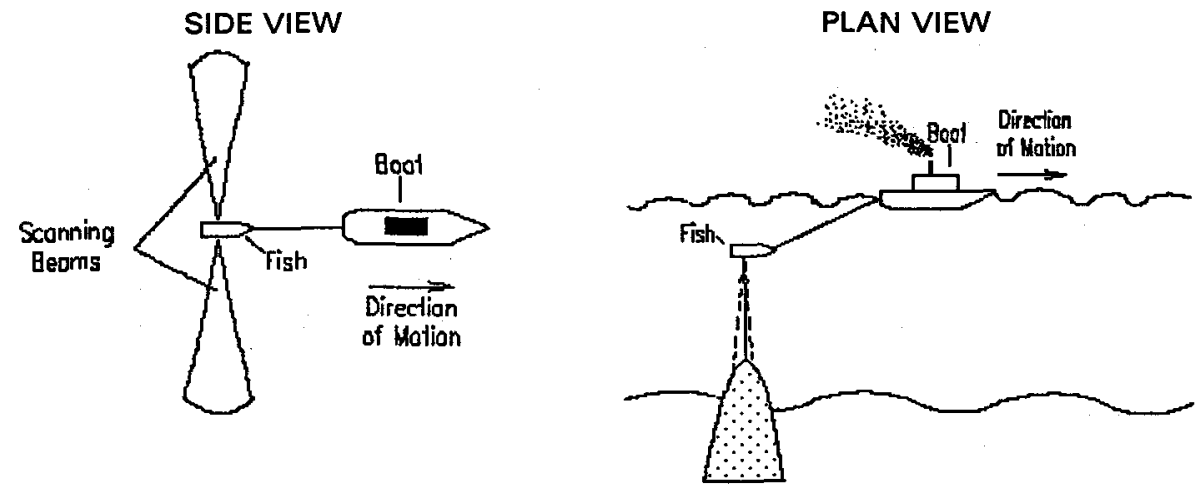

FIG 1 Showing the Geometry of a Side-Scan sonar. 
By coherently combining the returns at several sampling positions the synthetic aperture technique produces an effective beam-width much narrower than that of the real antenna. A comparison of the theoretical performances of synthetic aperture sonar against to the nonsynthetic aperture sonar can be found in [1] and [2].

The use of synthetic aperture techniques in side-scan radar are now commonplace [3] but their use in sonar is, as yet, restricted to research projects with no commercial systems known to the authors. To make a useful synthetic aperture sonar, it will be necessary to implement the processing in real time. Previous investigations into synthetic aperture sonar have performed the synthetic aperture processing off-line [4], [5], [6]. Another investigator [7] determined the processing requirement for a narrow-band synthetic aperture sonar in terms of the map-azimuth resolution. This paper extends the result to cover wide-band systems, and presents the processing in terms of the fundamental parameters of the sonar. The result can then be used when choosing the parameters for the sonar system to calculate their impact on the processing requirement.

\section{PROCESSING REQUIREMENT}

We assume that the processing is performed on every sample in the line, and that the length of the synthetic aperture is given by the lowest frequency in the transmitted pulse. The length of the synthetic aperture $L_{s a}$ for an object at a slant range $R$ from the antenna is given by:

$$
L_{s a}=\frac{\lambda_{\max } R}{D}
$$

where $D$ is the length of the real antenna on the fish and $\lambda_{\max }$ is the maximum wavelength of the frequency band in the transmitted pulse.

Then:

$$
\mathrm{N}_{\mathrm{sa}}=\frac{\mathrm{L}_{\mathrm{sa}}}{\delta_{\mathrm{s}}}=\frac{\lambda_{\max } \mathrm{R}}{\mathrm{D} . \delta_{\mathrm{s}}}
$$

where $\mathrm{N}_{\mathrm{sa}}$ is the number of samples that contribute to the focussing on one point. To calculate the number of operations that need to be performed on the whole line $\mathrm{N}_{\text {tot }}$, we sum the aabove equation across the whole range:

$$
N_{\text {tot }}=\underset{\Sigma}{R_{\min }}\left(\frac{\lambda_{\max } R}{D . \delta_{s}}\right)=\frac{\lambda_{\max } \cdot\left(R_{\max }+R_{\min }\right)}{2 D \cdot \delta_{s}} \cdot \frac{2 .\left(R_{\max }-R_{\min }\right) \cdot f_{s}}{C}
$$

now $f_{s}$ is the sampling frequency, i.e $f_{s}=k_{0} . f_{c}$, where $f_{c}$ is the centre frequency and $k_{o}$ is the over-sampling rate, $\delta_{\mathrm{s}}=\nu /$ prf where $\nu$ is the boat velocity and prf is the pulse repetition frequency, and:-

$$
\lambda_{\max }=\frac{C}{f_{\min }}=\frac{C}{f_{c}(1-1 / 20)}
$$

Where $Q$ is the quality factor of the transmitted pulse $\left(Q=\right.$ Bandwidth/f $\left.f_{c}\right)$ Substitute these into (3):

$$
N_{\text {tot }}=\frac{k_{0 . p r f .}\left(R_{\max }{ }^{2}-R_{\min }{ }^{2}\right)}{D \nu \cdot(1-1 / 2 Q)}
$$

This equation gives the number of focussing operations required to process a complete line, to find the rate of processing $M$, we need to multiply the number of computations per line by the number of lines per second. i.e $M=N_{\text {tot }} \times$ prf. We can also say that:

$$
\text { prf }=\frac{C}{2 \cdot R_{\max }}
$$

Multiply (5) by prf and substitute (6) into (5) gives: 
$M=\frac{k_{0} \cdot C^{2}}{4 . D v \cdot(1-1 / 2 Q)} \times \frac{\left(R_{\max }{ }^{2}-R_{\min }{ }^{2}\right)}{R_{\max }{ }^{2}}$

It can be shown that this result agrees with the result presented by Lee [7] for the narrow-band case. It should be noted that all of the ranges are slant ranges and thus the swath of sea-bed covered by the sonar is not given by $R_{\max }-R_{\min }$.

TYPICAL VALUES

$D=2 \mathrm{~m}, v=1 \mathrm{~m} / \mathrm{s}, k_{\mathrm{o}}=5, Q=1.5$ (i.e 1 Octave), $R_{\max }=750 \mathrm{~m}, R_{\min }=100 \mathrm{~m}$

Substituting these values into equation (7) above gives 2.1 Million operations per second! This result in itself is fairly meaningless without knowing the complexity of an operation. In fact an operation involves finding a point that corresponds to the current focussing point, extracting it from memory and adding it to an accumulator. Thus, focusing on a point can take many computer instructions.

\section{MEMORY REOUIREMENT}

In addition to the processing requirement, an important consideration for the processing system is the total memory capacity needed to store the data. This section derives an equation which can be used at the sonar design stage to predict the impact that the relevant sonar parameters have on the memory requirement. The number of samples which must be stored per line is given by:

thus:

$$
\text { samples/picture }=\text { samples/line } \times \text { lines/picture }
$$

$$
\text { samples/picture }=\frac{f_{s}}{\text { prf }} \cdot \frac{\lambda_{\max } \cdot R_{\max }}{D \cdot \delta_{s}}
$$

Where $\delta_{\mathbf{s}}=\nu /$ prf, also

$$
R_{\max }=\frac{C}{2 . p r f}=\frac{C \cdot D}{4 . \nu}
$$

and :

$$
f_{s} \lambda_{\max }=\frac{k_{0} \cdot C}{1-1 / 20}
$$

Thus:

$$
\text { samples/picture }=\frac{k_{0} \cdot C^{2}}{4 . \nu^{2}(1-1 / 20)}
$$

\section{TYPICAL VALUES}

Using the same parameters as above: $D=2 \mathrm{~m}, \nu=1 \mathrm{~m} / \mathrm{s}, k_{0}=5, Q=1.5$ (i.e 1 Octave), $R_{\max }=750 \mathrm{~m}, R_{\min }=100 \mathrm{~m}$; then the amount of memory required is approximately 4 Mbytes assuming 8 bits per sample.

\section{BENCHMARK TESTING}

To evaluate accurately the processing requirement it is necessary to know the execution time for one operation. In theory this could be done by counting the number of instructions for one operation and then calculating the time taken to perform these instructions. Unfortunately, with modern processor architectures, which have complicated pipelining systems for instruction execution, it is very difficult to calculate the time taken to perform a complicated algorithm, thus the best way is to run the algorithm which would be used for synthetic aperture processing on a real machine and time it.

A simulation program was written in $C$ consisting of two parts, the first, generating received sonar data from a simulated sea-bottom, the second, implementing the synthetic aperture processing algorithm to reproduce an image of the sea-bottom from the simulated sonar data. The algorithm was timed on several processors. Where possible hardware timers were 
used to obtain the timing of the second part of the simulation program. When hardware timers were not available, the whole program was timed, and then the program was timed again without the second part of the simulation, when these two timings are subtracted the time taken for the second part of the simulation is obtained. The results of these tests are shown in table1. The tests were based on the following processing parameters:

Max Range : 100m; Min Range : Om; Boat speed : $2 \mathrm{~m} / \mathrm{s}$ (4 knots); Array Length : $1 \mathrm{~m}$; Centre Frequency : $50 \mathrm{kHz}$; Over-Sample : 1; Number of platform positions stored : 60; Number of platform positions processed : 30

These parameters are much easier to process than the typical parameters shown in the previous, based on further simulation results and on the formula derived above, we would expect the processing to be five times greater than the simulation and to perform the processing for the typical parameters above in real time, a processor would need to be capable of performing the simulation program in $400 \mathrm{~ms}$. Using this, we can calculate the number of processors required for real-time execution. These figures are shown in table 1.

Table 1 . Time taken by various processors to implement the synthetic aperture algorithm.

\begin{tabular}{|l|l|l|l|l|}
\hline Name & $\begin{array}{l}\text { Timing with } \\
\text { process (s) }\end{array}$ & $\begin{array}{l}\text { Timing } \\
\text { without } \\
\text { process (s) }\end{array}$ & Difference (s) & $\begin{array}{l}\text { No. of } \\
\text { processors } \\
\text { required }\end{array}$ \\
\hline $\begin{array}{l}\text { Mototorola 68030 with } \\
68882 \text { co-processor }\end{array}$ & 73.2 & 41.3 & 31.9 & 80 \\
\hline Sparc1 & 22.4 & 12.8 & 9.6 & 24 \\
\hline Intel i860 & 5.08 & 3.25 & 1.83 & 5 \\
\hline Inmos T801 (20MHz) & - & - & 12.3 & 31 \\
\hline $\begin{array}{l}\text { Motorola 88000 } \\
\text { (16k cache) }\end{array}$ & - & - & 8.0 & 20 \\
\hline
\end{tabular}

\section{CONCLUSIONS}

We have shown that synthetic aperture processing of side-scan sonar data is possible in real-time with a favourable choice of sonar parameters. We have also derived expressions which allow the designer of synthetic aperture systems to predict the impact of his choice of sonar parameters on the processing system.

\section{ACKNOWLEDGMENTS}

This work has been funded by the European community's MAST program and is part of the ACID project.

\section{REFERENCES}

[1] Lois. J. Cutrona "Comparison of sonar system performance using synthetic-aperture techniques with the performance achievable by more conventional means" J. Acoust. Soc. Am., Vol. 58, no. 2 pgs 336-348.

[2] Lois. J. Cutrona "Additional characteristics of synthetic-aperture sonar systems and a further comparison with nonsynthetic-aperture sonar systems" J. Acoust. Soc. Am., Vol. 61, no. 5, pgs 1213-1217.

[3] Kiyo Tomiyasu "Tutorial Review of Synthetic-Aperture Radar (SAR) with Applications to Imaging of the Ocean Surface". Proc. IEEE, Vol. 66, no. 5, pgs 563-584.

[4] Nai-Chyuan Yen, William Carey "Application of synthetic-aperture processing to towed-array data." J. Acoust. Soc. Am. vol 86, no. 2, pgs 754-765.

[5] Ross. E. Williams, "Creating an acoustic synthetic aperture in the ocean." J. Acoust. Soc. Am. vol 60, no. 1, pgs 60-73.

[6] Peter.T. Gough and Michael.P. Hayes "Test results using a prototype synthetic aperture sonar.". J. Acoust. Soc. Am. vol 86, no. 6, pgs 2328-2333.

[7] Henry. E. Lee. "Extension of Synthetic Aperture Radar (SAR) Technique to Undersea Applications", IEEE-OE, vol. 4, no. 2, pgs 60-63. 